\title{
Test Readiness Diagnostics
}

\author{
David N. Fittinghoff, Mark J. May \\ and Ronnie Shepherd
}

\author{
Lawrence Livermore National Laboratory \\ May 5, 2004
}


This document was prepared as an account of work sponsored by an agency of the United States Government. Neither the United States Government nor the University of California nor any of their employees, makes any warranty, express or implied, or assumes any legal liability or responsibility for the accuracy, completeness, or usefulness of any information, apparatus, product, or process disclosed, or represents that its use would not infringe privately owned rights. Reference herein to any specific commercial product, process, or service by trade name, trademark, manufacturer, or otherwise, does not necessarily constitute or imply its endorsement, recommendation, or favoring by the United States Government or the University of California. The views and opinions of authors expressed herein do not necessarily state or reflect those of the United States Government or the University of California, and shall not be used for advertising or product endorsement purposes.

This work was performed under the auspices of the U.S. Department of Energy by the University of California, Lawrence Livermore National Laboratory under Contract No. W-7405-Eng-48. 


\section{The goal is to reduce the time required to field a underground test}

- Initial target is a 24 month Readiness Posture

- With approval, transition to an 18 month Readiness Posture by the end of FY 2005

- This work involves close coordination with other organizations

- LANL

- SNL

- Bechtel Nevada 


\section{To help organize our efforts, LLNL is designing Operation Popout}

Goal: to build test specific expertise by developing a containment plan, line of sight designs, detector coverage's and shielding designs for a hypothetical test

- Simple to moderately complex test

- Assumes Gabbs canister modified to support the test

- Prototypes of replacement technology fielded in parallel with legacy systems

- Add-on experiments at each lab

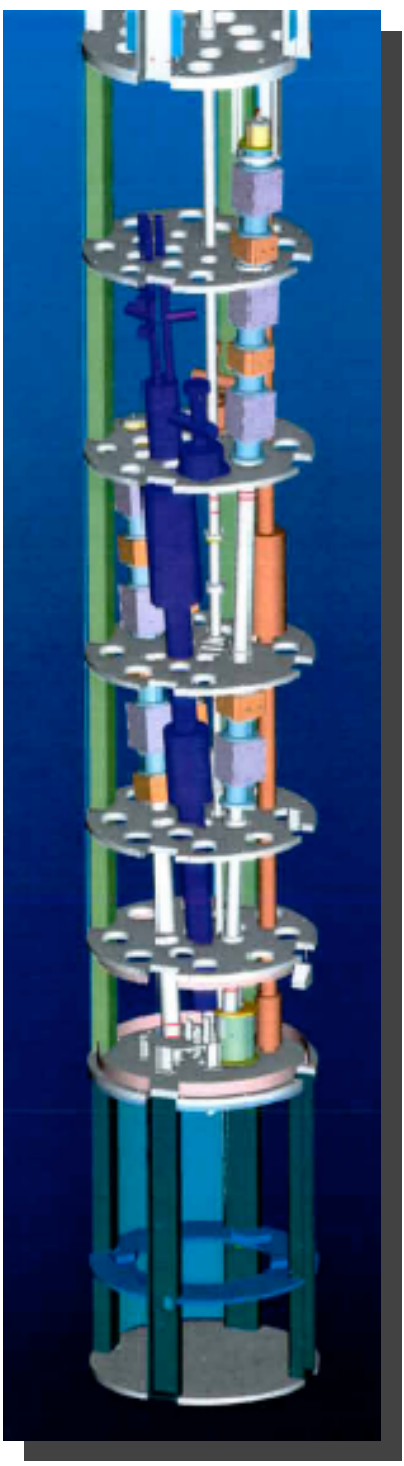




\section{[4- \\ While other issues exist, V-division only deals directly with diagnostics}

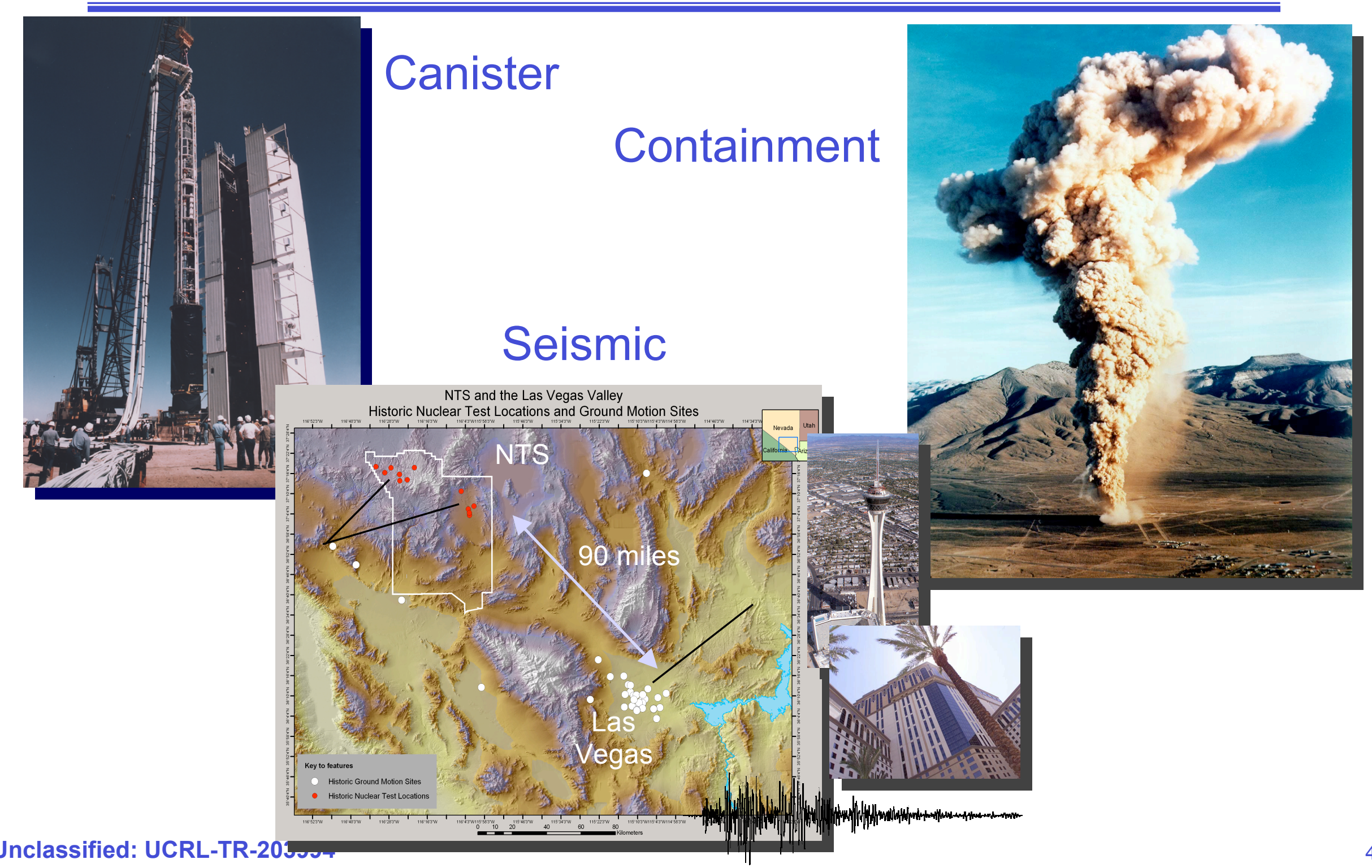




\section{A moderately complex test requires a suite of diagnostics}

- Reaction History

PINEX/TENEX

- Radiochemistry

- PINEX

- Captains/THREX

- NUEX

- Others

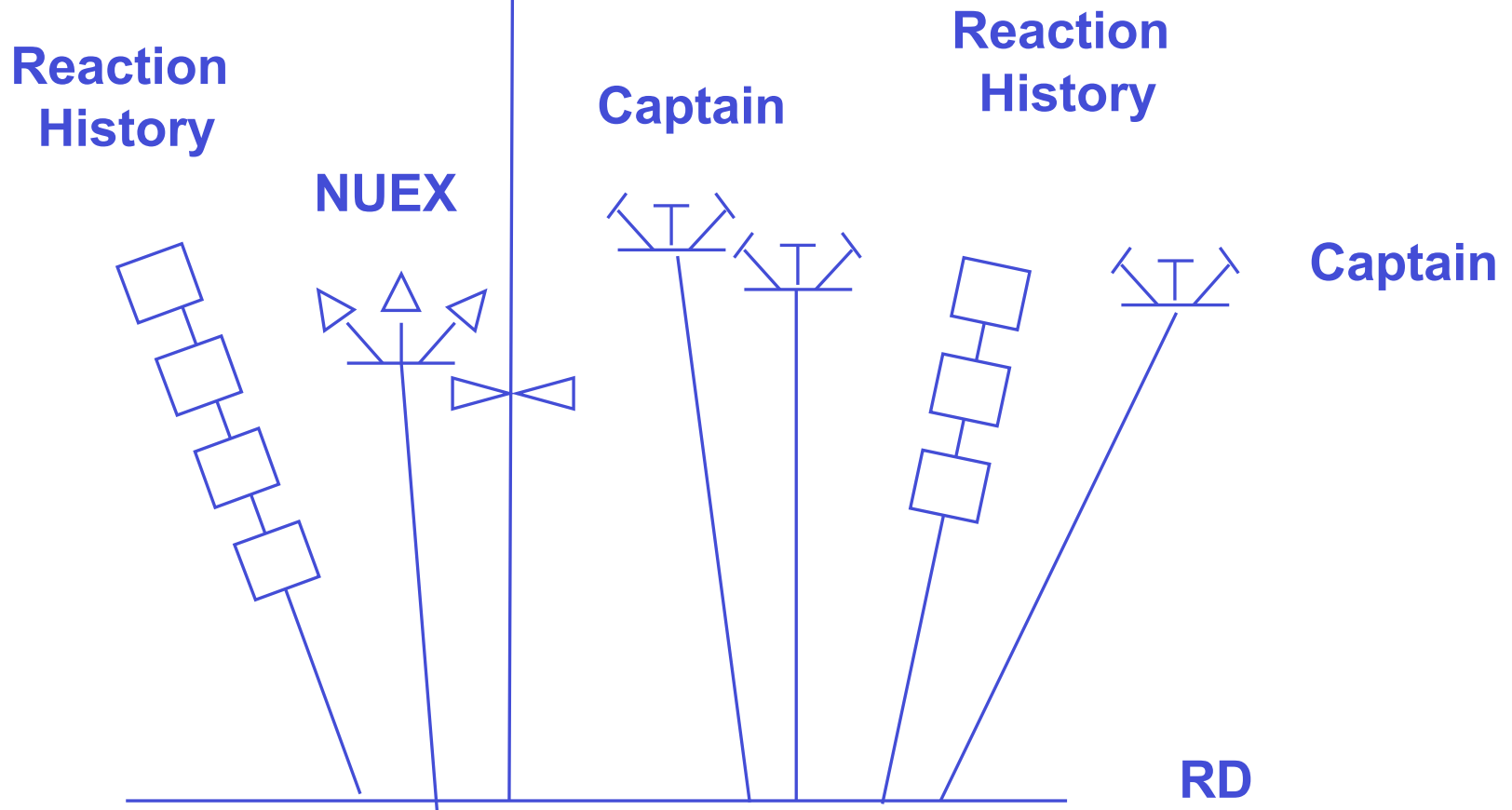




\section{For the current TR diagnostics funding, we can...}

- Reconstitute Reaction History

- Reconstitute limited PINEX

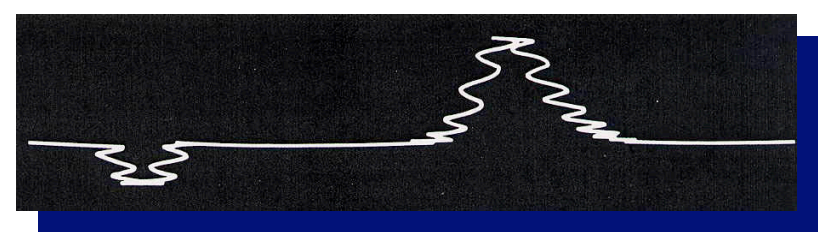

- Reconstitute radiochemistry

- Delayed Captains/Threx to Sept. 30, FY07

- NUEX may be supported in 18 months 


\section{Achieving a 24 month posture on diagnostics involves several hurdles}

- There are limited supplies of legacy equipment.

- 2-3 shots maximum

- The equipment that does exist is old and increasingly unreliable.

- Testing

- Replacement

- Key items

- Rossi scopes

- PINEX cameras

- Cable (800k feet RF-19)

Designers always want better resolution in every variable 


\section{Reaction History is a measurement of the gamma rays over time.}

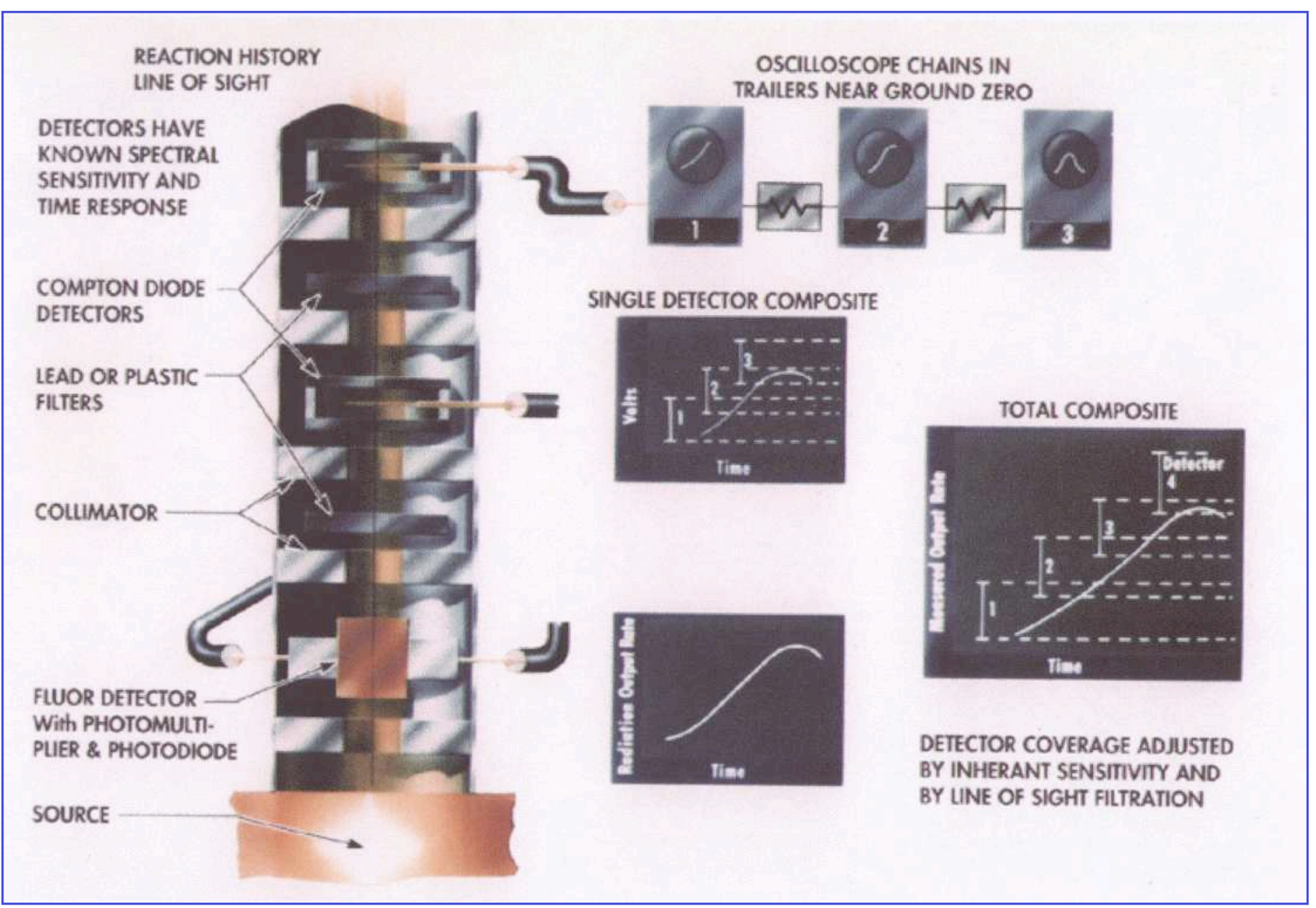




\section{Reaction History tasks}

Goal: to develop the people and required component replacement technology to field reaction history on an underground nuclear test

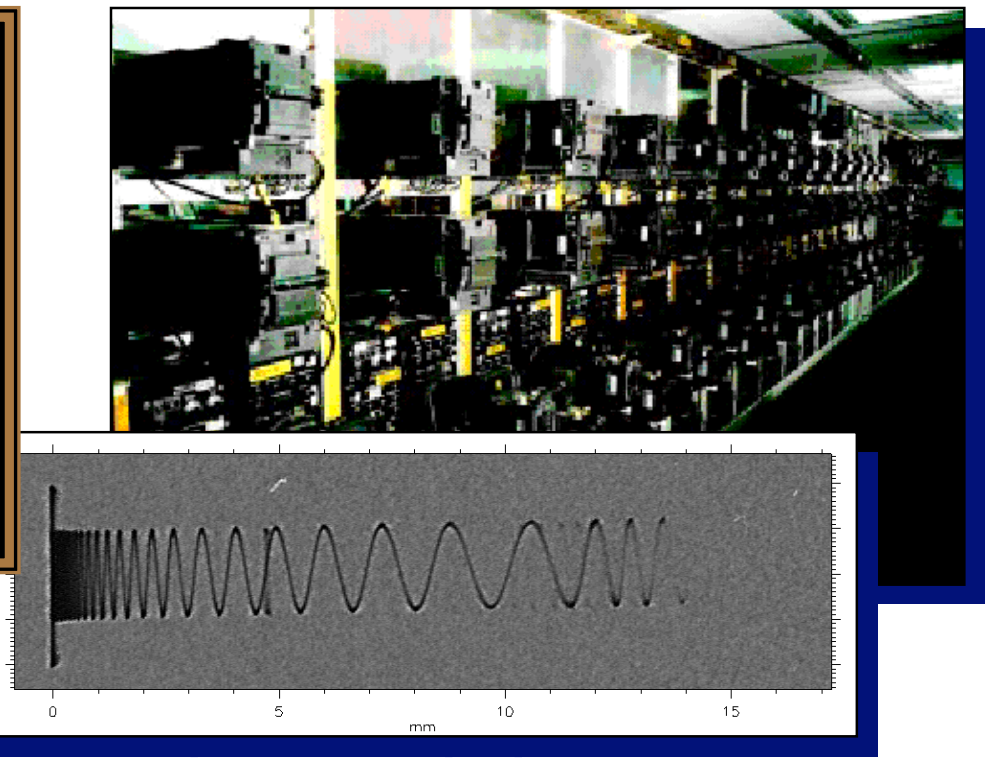

- Identify and qualify replacement cable and detectors

- Evaluate digital techniques for RH measurements

- Identify film or CCD replacements for scope cameras

- Develop high bandwidth reaction history

- Line-of-sight calculations 


\section{We looked into the present status of the legacy equipment.}

- VCDs

- At least one of VCDs is no longer

- under vacuum.

- Inventory reliability is in question

- BN to manufacture new ones

- Cable (RF-19)

- Sitting in desert for 10 years

- Deteriorating insulation

- Rossi Scopes

- Recent BN tests look promising
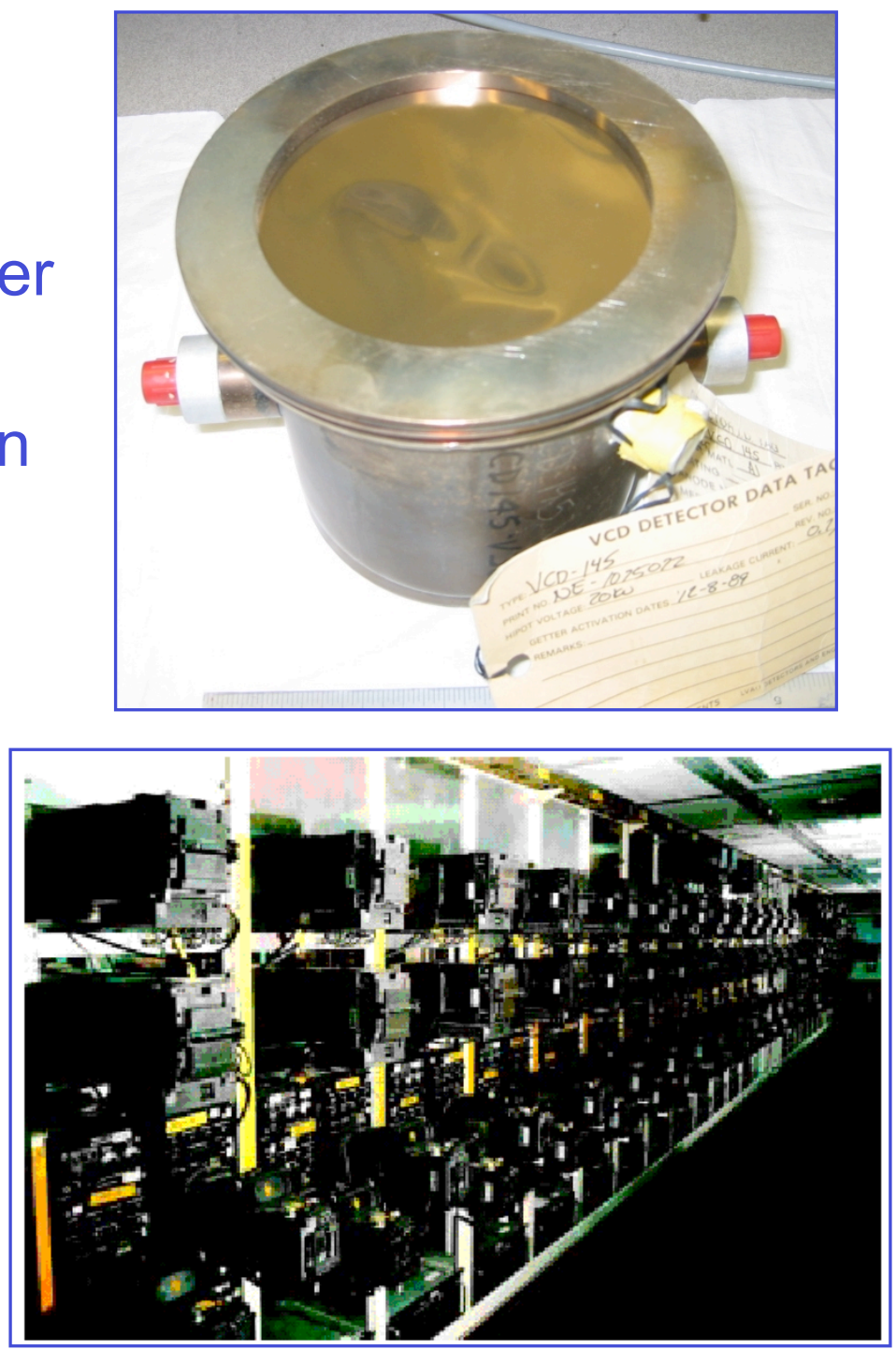


\section{We are reconstituting the ability to calibrate detectors.}

Photometric Sensitivity

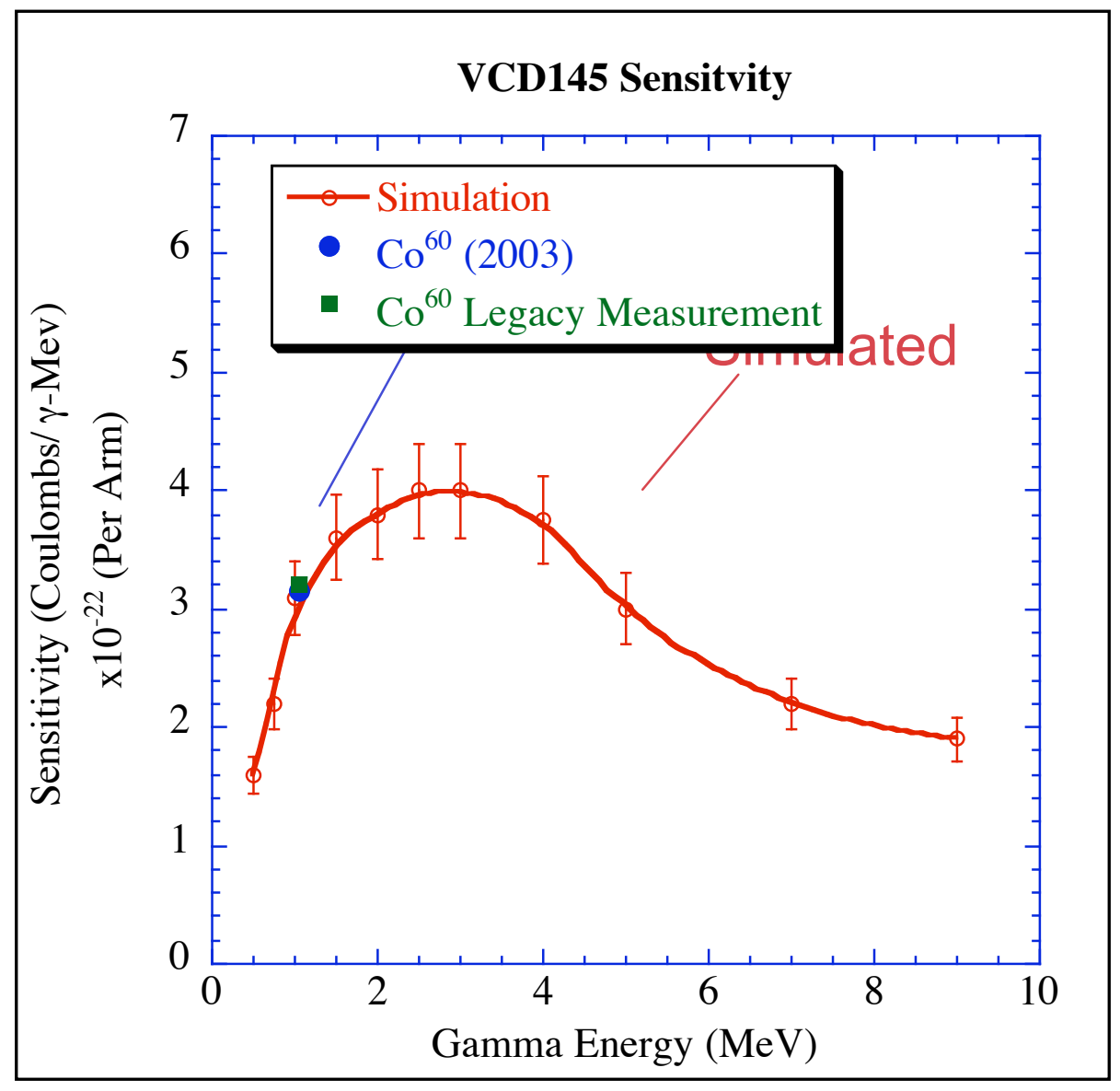

Legacy Temporal Response

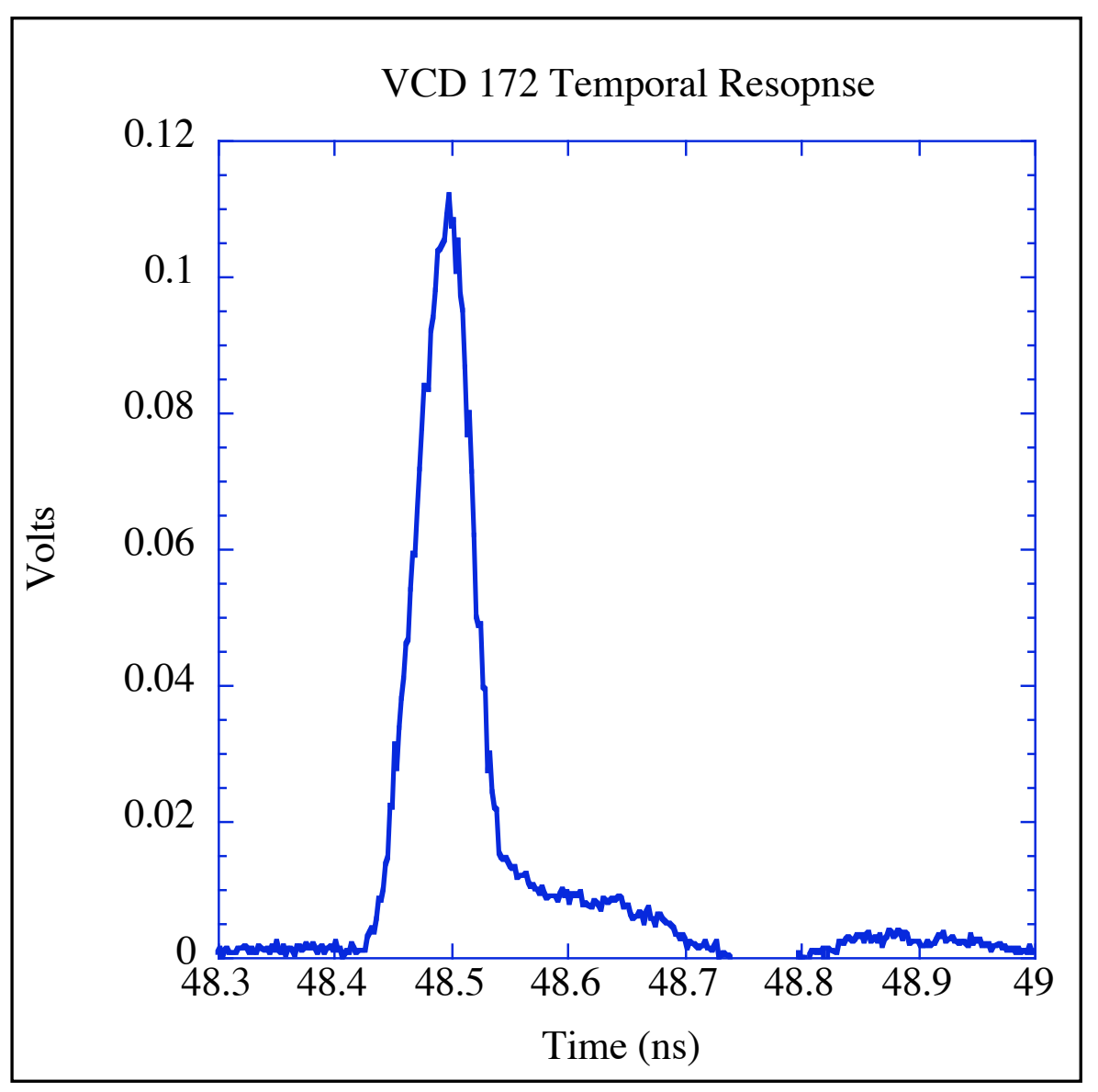




\section{We are investigating the status of the stockpile of RF-19 Cable}

- Mechanical Properties unknown

- Failed gas block

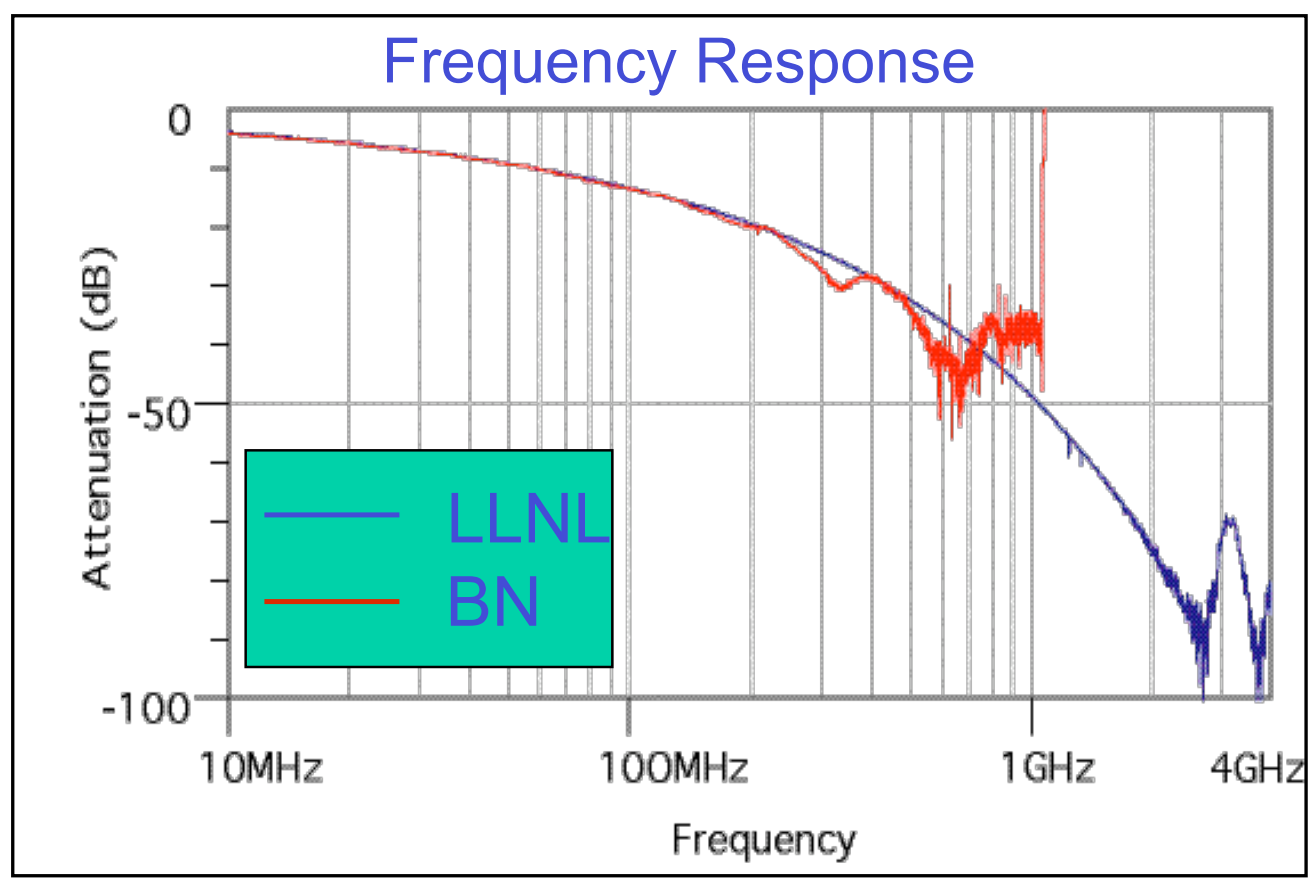

Passed High Voltage

$20 \mathrm{kV}$ for $1 \mathrm{~min}$

I(leakage) $0.5 \mathrm{uA}$,

$\mathrm{I}($ minimum $) \sim 21.4 \mathrm{uA}$ 


\section{The Modern Reaction History Measurement}

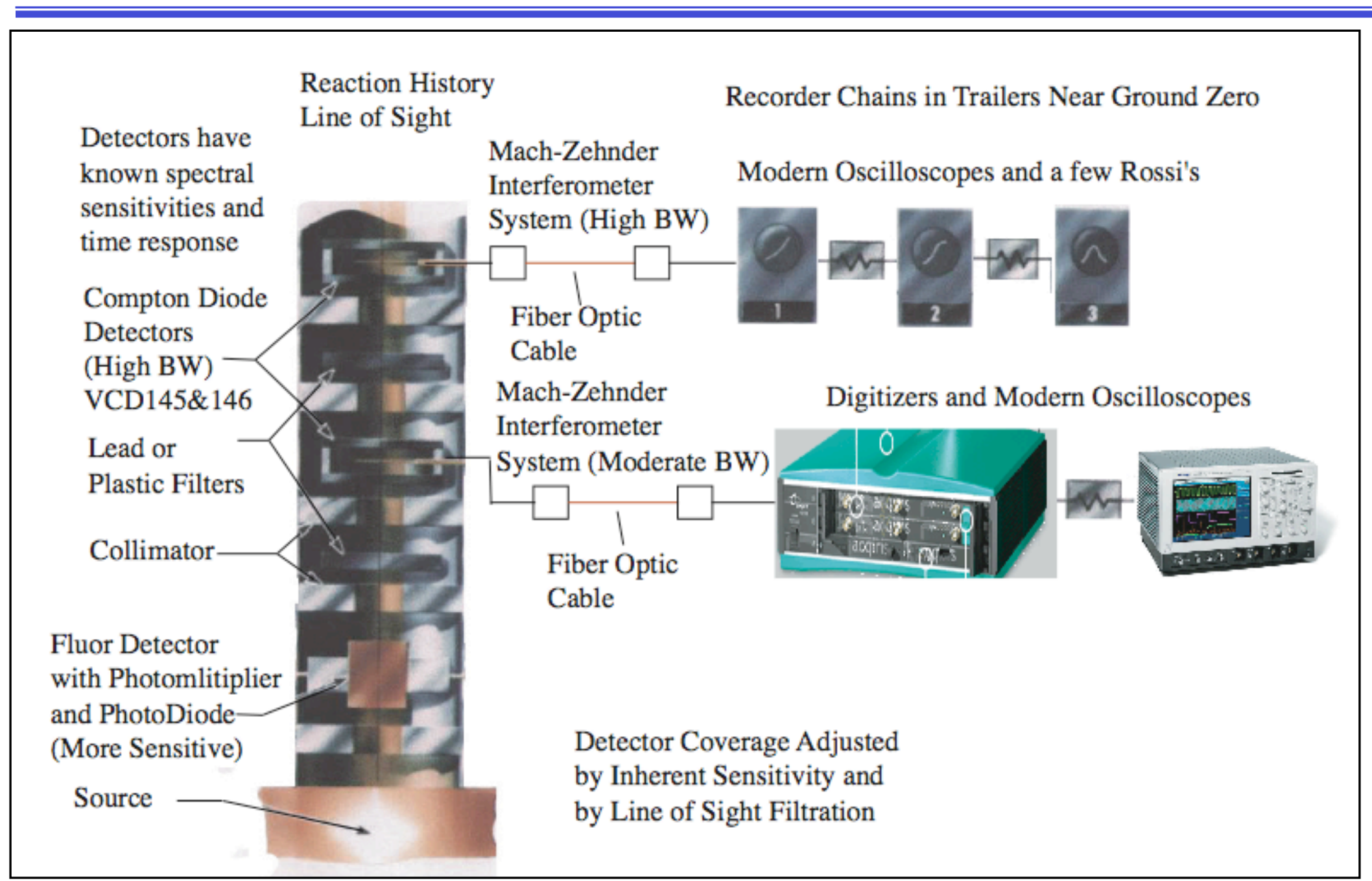




\section{Reaction History accomplishments}

- Completed first calibration of a vacuum Compton diode since the end of testing

- Developed ability to run GNARM for determining detector signal levels for lines-of-sight

- Completed high-frequency characterization of legacy RF-19 cable; designing and simulating prototype equalizer components

- Completed high bandwidth component survey

- Evaluated three digitizers for possible Rossi replacement 


\section{PINEX: a pinhole camera image of the device neutron emission}

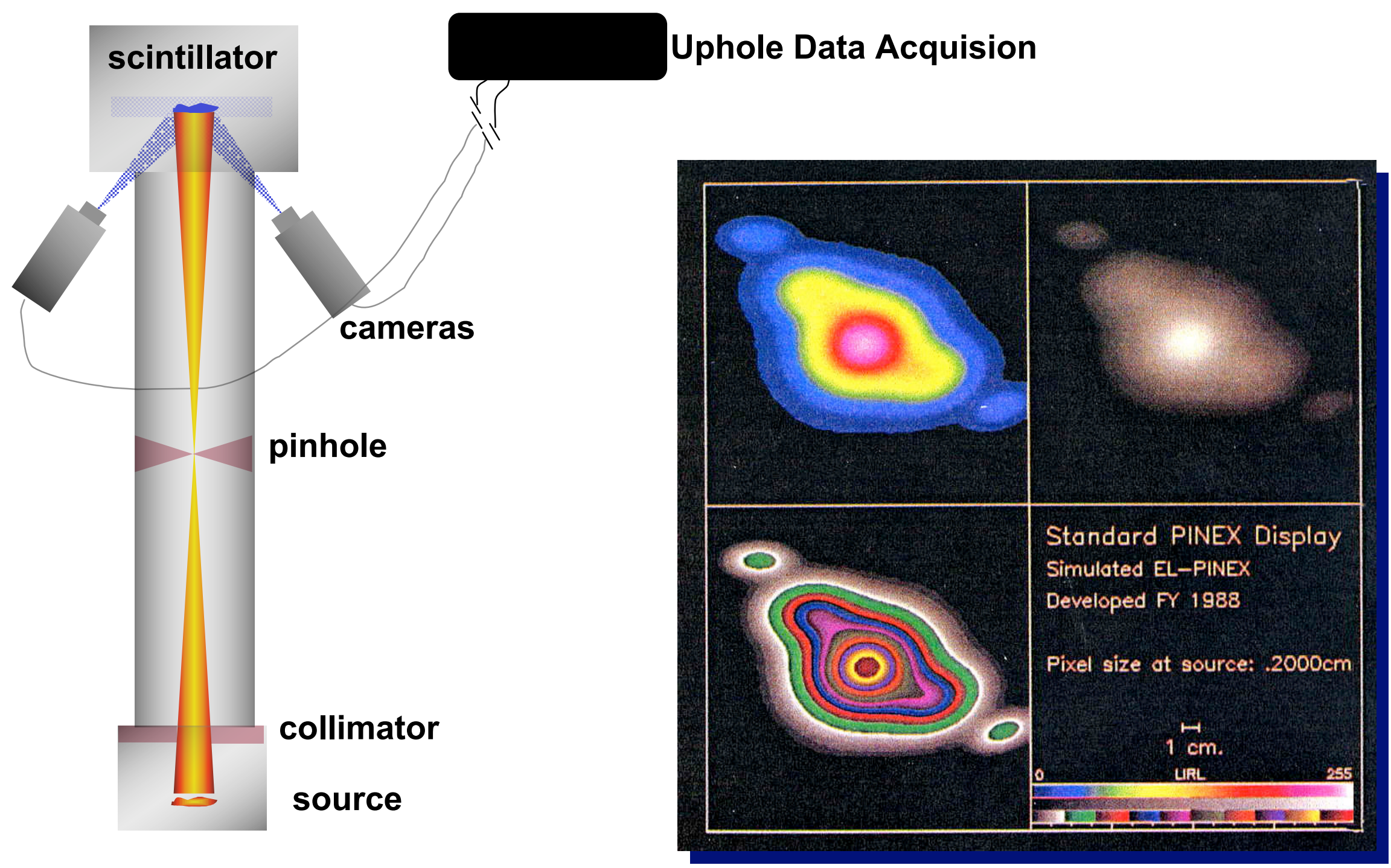




\section{PINEX tasks}

- Develop new fast readout camera

- Identify and qualify scintillator replacement

- Identify and qualify replacement MCP vendor

- Develop modern data acquisition system requirements

- Evaluate status of data acquisition components

- Evaluate pinhole fabrication

The cameras are a critical issue

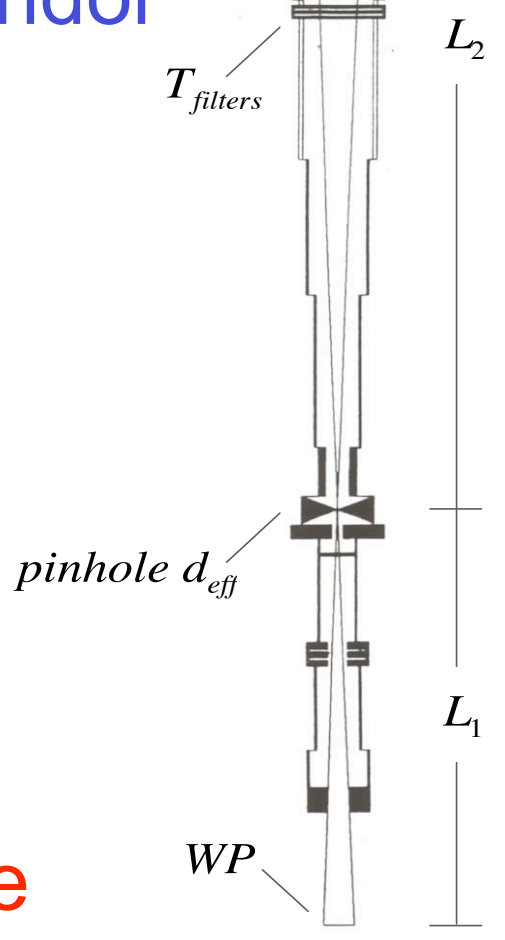




\section{Only enough legacy cameras for 2 tests, so a replacement is needed.}

- Legacy 128 x128 Reticon Diode Arrays

- Image readout in approximately 2 msec before shock destroys the cameras.

- High radiation background.

- Moderate resolution ( $400 \mu \mathrm{m}-500 \mu \mathrm{m})$

- Moderate dynamic range ( 100)

- Replacement Specification

- Image readout in approximately 2 msec before shock destroys the cameras.

- High radiation background.

- Improved resolution $(200 \mu \mathrm{m}-300 \mu \mathrm{m})$

- Increase dynamic range- ( 1000)

- Time resolution- 2-3 ns 


\section{Our approach is to field both legacy and developmental systems}

- ANY new system should be bench-marked!

- Shots will most likely be rare if program is restarted

- Previous systems were time tested

- New people + New system+ Added features $=(\ldots)$

- New system is required to move forward

- Readout cameras with better spatial resolution

- Faster data acquisition

- Much more storage capabilities 


\section{Using new cameras makes radiation hardness an issue}
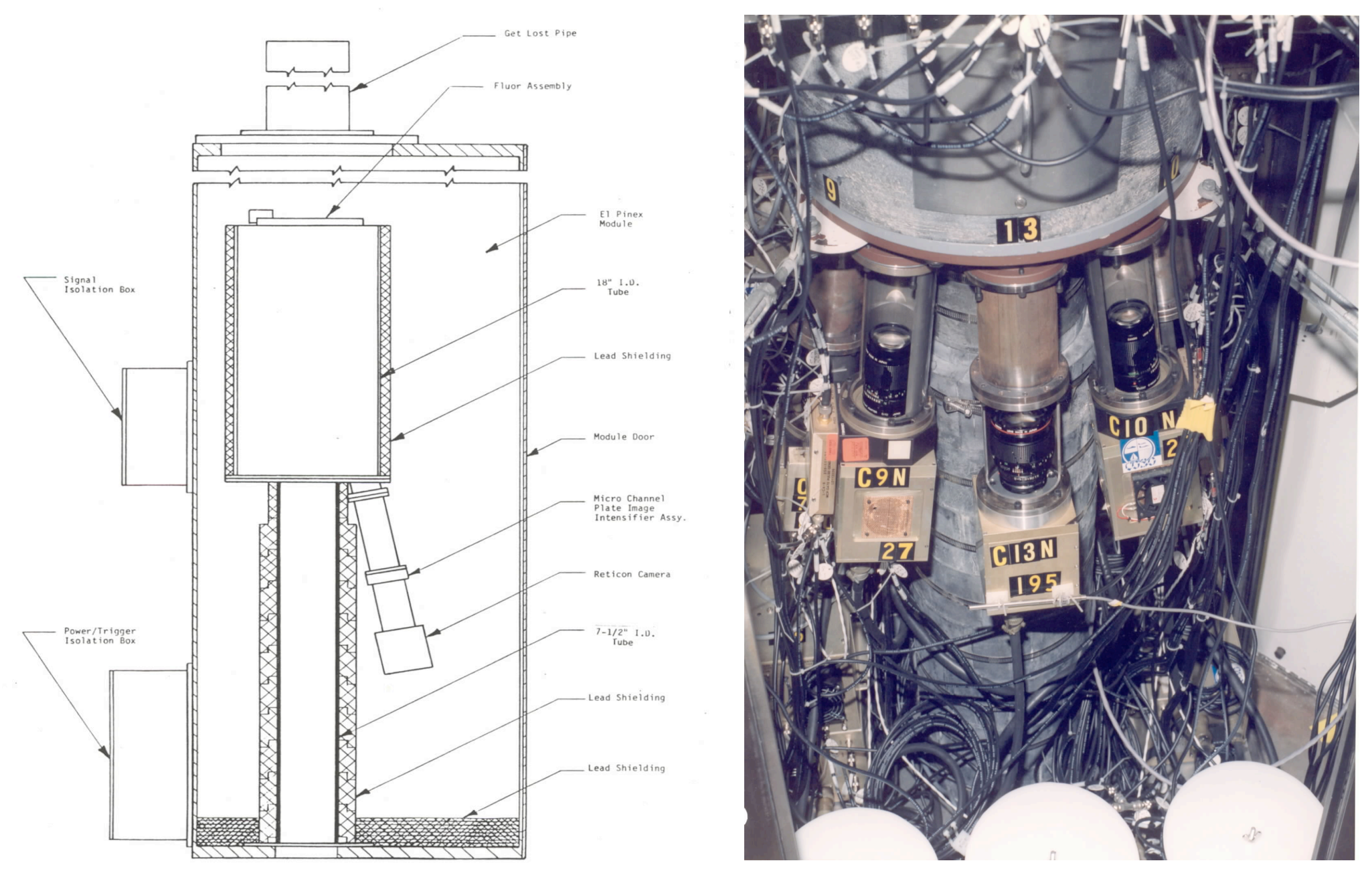

- Courtesy of J. Hall 


\section{Using new cameras makes radiation hardness an issue}

- Tests on the neutron susceptibility of the CMOS cameras are being designed.

- The system we will use will use a short fiber optic relay to rotate the camera chip away from the scintillator to minimize potential "starring".

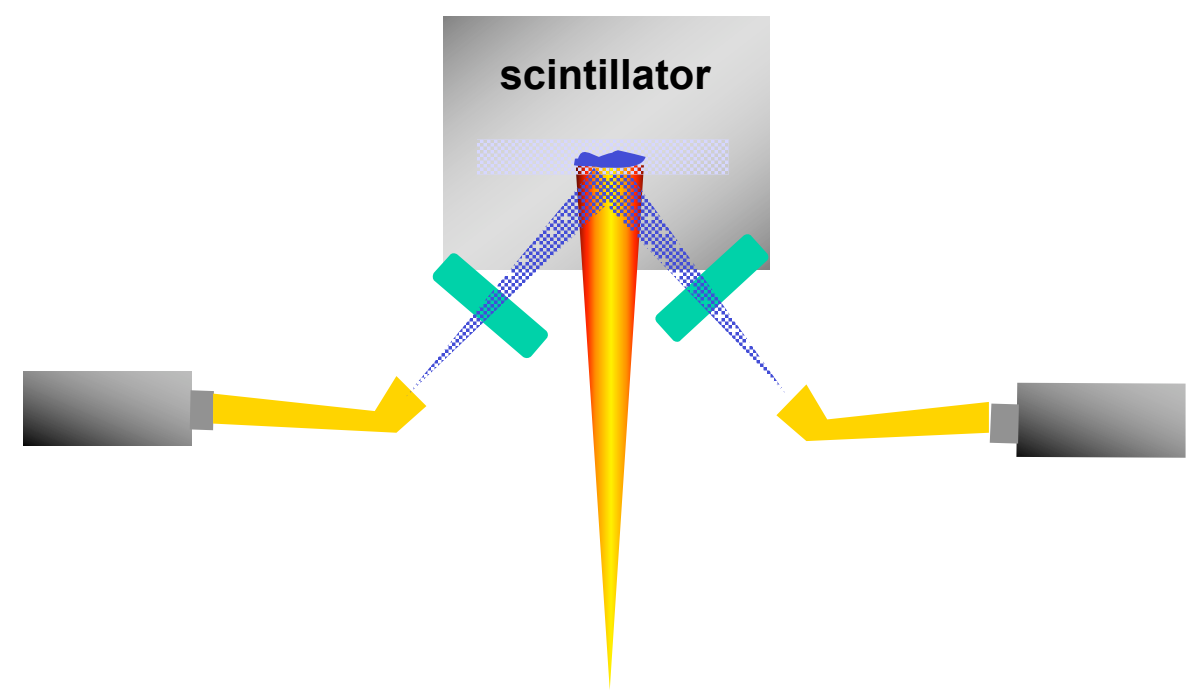




\section{Pinhole considerations play an central role in the design}

- The pinhole is the limiting factor in the system resolution

- The pinhole is the limiting factor in the source solid angle

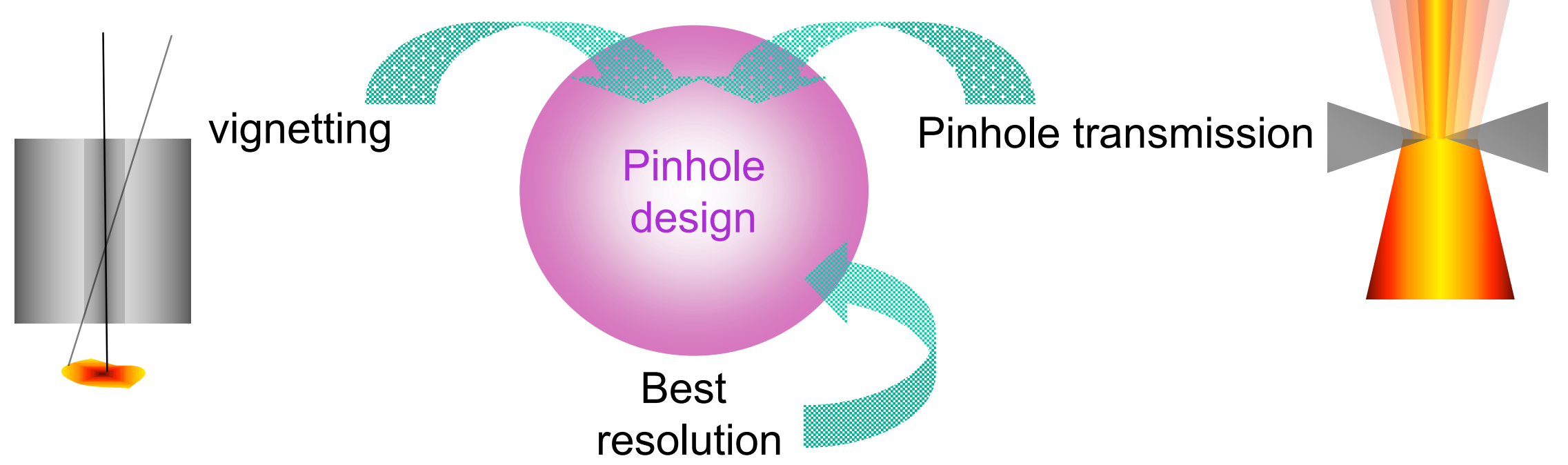

We are investigating newer designs used on OMEGA 


\section{[L] We are using Monte Carlo simulations to investigate resolution}
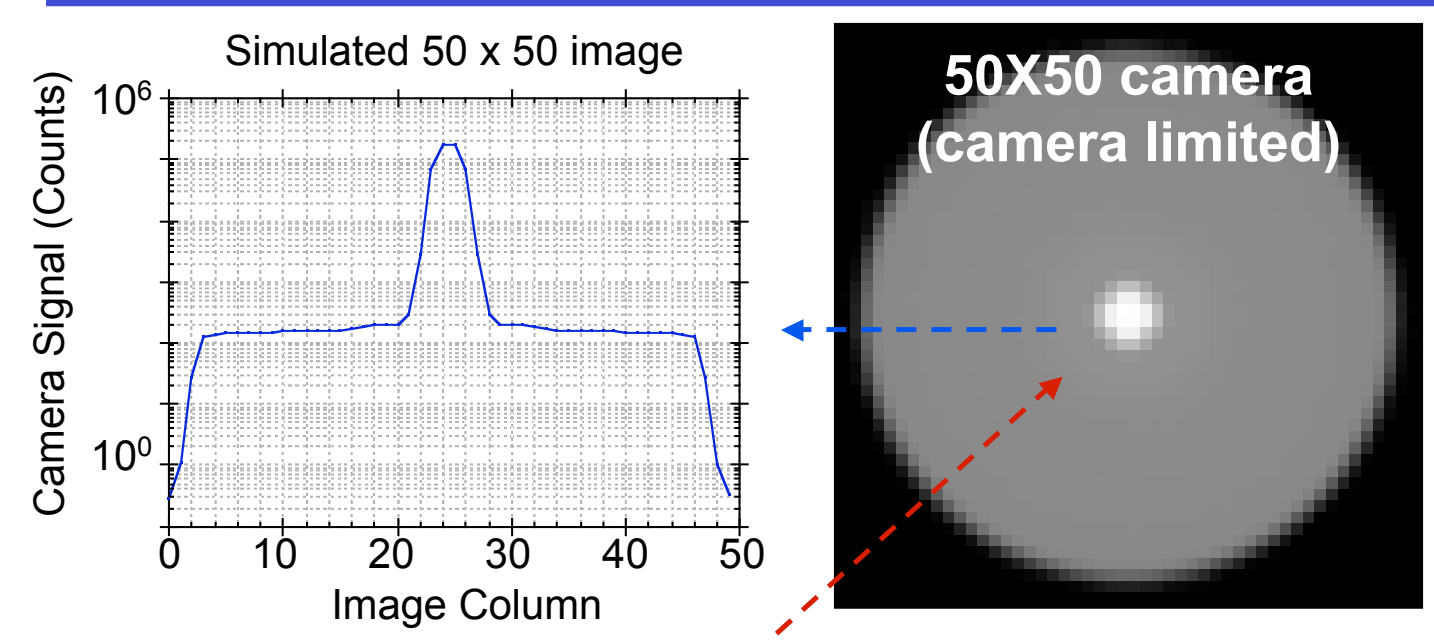

Source hot spots
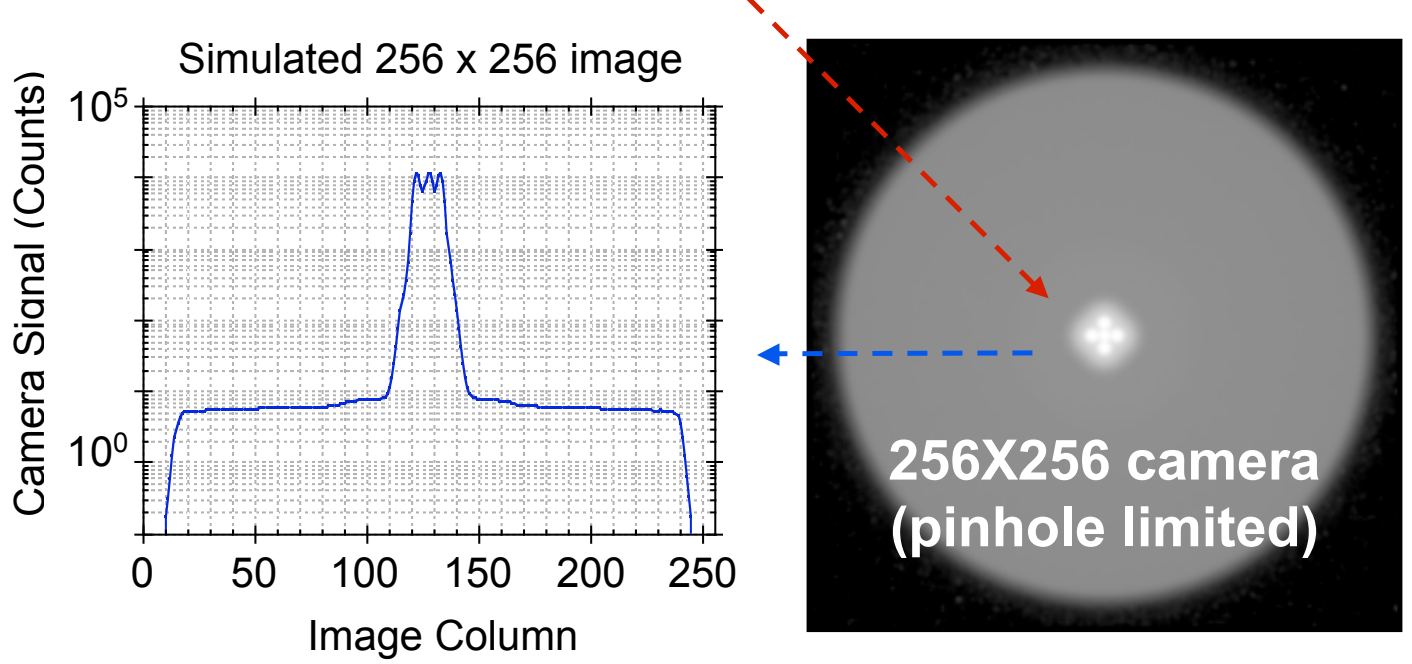

$>512 \times 512$ does not help due to other limitations

$2.50 \mathrm{~cm} \varnothing$ source
0.014" pinhole @ 250"
fluor @ 1000" (M = 3:1)

Also aiding in determining scattered signals 


\section{PINEX Accomplishments}

- Established baseline camera resolution requirements

- Developed preliminary PINEX design based on commercial chip technology

- Developed neutron testing plan for commercial chip

- Completed preliminary optical characterization of commercial system-failed

- Completed preliminary design of data acquisition system 


\section{Spin-off collaborations:}

- Jasper pin upgrade

- Improved high-speed electronics for the EOS experiments.

- Fiber re-circulator tech base project

- May allow $\sim 40-\mathrm{GHz}$ (analog bandwidth) sampling a transient.

- Alpha Box

- Portable Reaction History Detection

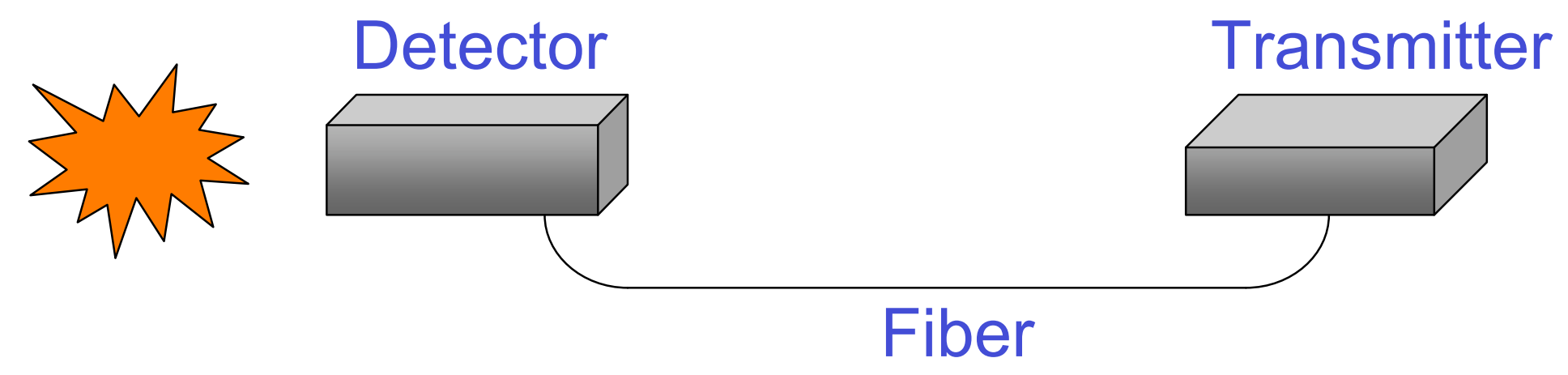

